Check for updates

Cite this: Mater. Adv., 2020 1,3532

Received 8th August 2020, Accepted 11th November 2020

DOI: $10.1039 / \mathrm{d} 0 \mathrm{ma00584c}$

rsc.li/materials-advances

\title{
Supramolecular assemblies of a 1,8-naphthalimide conjugate and its aggregation-induced emission property $\dagger$
}

\author{
Souvik Misra, (D) a Pijush Singh, (D) ${ }^{\mathrm{b}}$ Ankita Das, ${ }^{\mathrm{c}}$ Paula Brandão, (D) ${ }^{\mathrm{d}}$ Pathik Sahoo, ${ }^{e}$ \\ Nayim Sepay, (D) ${ }^{f}$ Gourab Bhattacharjee, (D) ${ }^{g}$ Pallab Datta, (D) ${ }^{c}$ Ajit K. Mahapatra, ${ }^{a}$ \\ Biswarup Satpati (D) ${ }^{g}$ and Jayanta Nanda (iD $\ddagger^{*^{a}}$
}

\begin{abstract}
The aggregation-induced emission (AIE) property has attracted considerable research interest since its discovery. Several small molecule-based AIE fluorogens (AIEgens) have shown unique properties. In this work, we are reporting for the first time a 1,8-naphthalimide (NMI) conjugate of a dipeptide, which is found to exhibit J-type aggregation in the solid and solution state, and also in the gel state. Unsubstituted naphthalimide units usually exhibit aggregation-caused quenching due to face-to-face stacking compared to ring-substituted ( $V$-shaped) derivatives. Here, the amide hydrogen bonding interaction present in the molecule guides the packing of unsubstituted naphthalimide units in the crystal structure and it is consistent with J-type aggregation. The self-assembly and gelation properties of the NMI derivative were studied in several pure and water-miscible mixed solvents. In the mixed solvents, gelation is caused by the anti-solvent effect. Aggregation-induced emission properties were observed upon addition of water in the water-miscible solvent solutions of the gelator. Finally, the AIE property of the NMI-peptide conjugate was used extensively for live-cell imaging.
\end{abstract}

\section{Introduction}

In the last two decades, the aggregation-induced emission $(\mathrm{AIE})^{1-7}$ properties of different fluorophore-based systems have been explored extensively owing to their wide-range of applications in different research areas including sensing, imaging, and theranostics. Most of the common and conventional

\footnotetext{
${ }^{a}$ Department of Chemistry, Indian Institute of Engineering Science and Technology, Shibpur, P.O. - Botanic Garden, Howrah-711103, West Bengal, India. E-mail: drjayantananda16@gmail.com

${ }^{b}$ Department of Biochemistry and Biophysics, University of Kalyani, Kalyani, Nadia, West Bengal, India

${ }^{c}$ Centre for Healthcare Science and Technology, Indian Institution of Engineering Science and Technology, Shibpur, P.O. - Botanic Garden, Howrah, India

${ }^{d}$ Departamento de Quimica/CICECO, Universidade de Aveiro, 3810-193 Aveiro, Portugal

${ }^{e}$ International Center for Materials and Nanoarchitectronics (MANA) and Research Center for Advanced Measurement and Characterization (RCAMC), National Institute for Materials Science (NIMS), 1-2-1 Sengen, Tsukuba, Japan

${ }^{f}$ Department of Chemistry, Jadavpur University, Jadavpur, Kolkata-700032, India

${ }^{g}$ Saha Institute of Nuclear Physics, 1/AF Bidhannagar, Kolkata,

West Bengal 700064, India

$\dagger$ Electronic supplementary information (ESI) available. CCDC 1991131. For ESI and crystallographic data in CIF or other electronic format see DOI: 10.1039/ d0ma00584c

\# Present address: Department of Chemistry, Kalimpong College, Kalimpong, West Bengal 734301, India.
}

organic aromatic fluorophores with planar structure show strong intermolecular H-type $\pi-\pi$ stacking interactions and relax via a non-radiative pathway, leading to aggregationcaused quenching (ACQ). Using such organic fluorophores in the fabrication of organic light-emitting diodes (OLEDs), scientists faced adverse problems, as these materials are aggregated in the thin films state, leading to the quenching of the fluorescence emission. For the first time in 2001, Tang et al. discovered an interesting photophysical phenomenon which was opposite to the effect of ACQ, known as aggregationinduced emission (AIE). ${ }^{8}$ Following this discovery, Park et al. (in 2002) reported an aggregation-induced emission enhancement (AIEE) phenomenon, ${ }^{9}$ caused by the synergetic effect of J-type aggregation and planarization. Recently, 1,8-naphthalimide (NMI), a naphthalene core with $N$-imide functionality, is considered as a promising fluorophore for various AIE-based applications ${ }^{10-20}$ as the NMI moiety possesses extraordinary thermal and chemical stability with a high fluorescence quantum yield. ${ }^{21}$ In a recent review, Gopikrishna et al. summarized that ring-substituted NMI compounds, which adopt mainly a V-shape, are highly fluorescent in the aggregated state. ${ }^{21}$ On the contrary, planar unsubstituted NMI compounds, generally highly fluorescent in solution, undergo strong face to face stacking in the aggregated state, which leads to quenching of the fluorescence due to the ACQ effect. 
To date, very few report on aggregation-induced emission of unsubstituted NMI-based molecule is known in the literature specifically in the solid state. ${ }^{13}$ Liu and co-workers reported a 1,8-naphthalimide-based molecule which showed intense blue emission in the solid-state. The molecules are arranged in a J-type manner due to the presence of weak non-covalent interactions. ${ }^{13}$ In this manuscript, we are presenting for the first time an unsubstituted NMI-conjugate of a dipeptide (NMIGW-OMe) which shows J-type aggregation ${ }^{22,23}$ and remarkable fluorescence properties in the solid state as well as in the selfassembled state.

\section{Results and discussion}

The chemical structure of NMI-GW-OMe is given in Scheme 1 and a detailed synthetic procedure and its characterization are reported in the ESI. $\dagger$ A light yellow coloured needle-shaped crystal was developed in $\mathrm{CHCl}_{3}$-methanol medium and the solid-state structure of NMI-GW-OMe was solved by the single crystal X-ray diffraction (SXRD) technique at $150 \mathrm{~K}$. It crystallizes in the orthorhombic space group $P 2_{1} 2_{1} 2_{1}$ with unit cell dimensions of $a=4.8611(3) \AA, b=15.2401(11) \AA, c=28.170(2) \AA$ and $V=2086.9(3) \AA^{3}$ (ESI, $\dagger$ Table S1). In the solid-state, an intermolecular amide hydrogen bonding $(\mathrm{N}-\mathrm{H} \cdots \mathrm{O}$, see Table S2, ESI $\dagger$ ) interaction is noticed. This strong hydrogen bonding interaction guides aromatic-aromatic interactions ${ }^{24}$ of unsubstituted NMI units (Fig. 1a). The $\pi-\pi$ stacking interaction distances (centroid to centroid) between naphthalimide and naphthalimide units and benzopyrrole and benzopyrrole units of the Trp group are $4.86 \AA$ in both cases. The slippage angle between the naphthalimide units is $46.37^{\circ}$ (ESI, $\dagger$ Fig. S6), which is less than the magic angle, $54.7^{\circ}$. Such a type of molecular

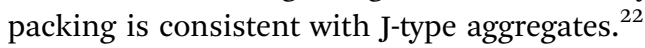

NMI-GW-OMe molecules are connected in a head to tail manner via weak intermolecular $(\mathrm{C}-\mathrm{H} \cdots \mathrm{O}$ hydrogen bonding) interactions between the aromatic naphthalimide unit and the Trp moiety of another molecule. The distance between the oxygen of naphthalimide and the tryptophan ring hydrogen is $2.612 \AA$ (Fig. 1b). On careful observation, it introduces a bend in the higher-order assembly, which leads to the formation of a supramolecular helical structure in the solid-state (Fig. 1c).

It is interesting to study the fluorescent property of a naphthalimide derivative which is arranged in the J-type
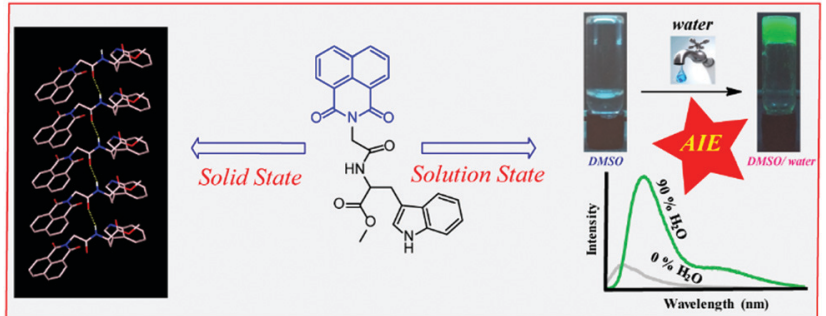

Scheme 1 Chemical structure of the studied naphthalimide derivative (NMI-GW-OMe) and its supramolecular assemblies in the solid and solution state. a)

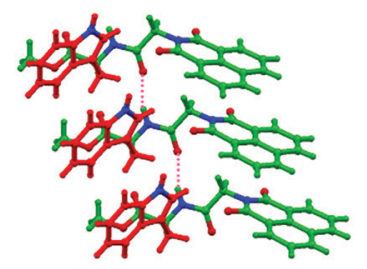

b)

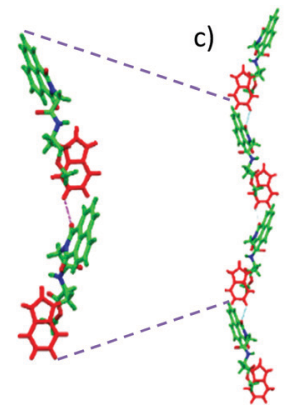

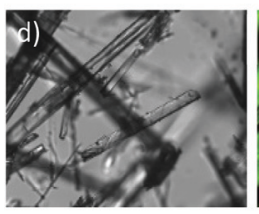
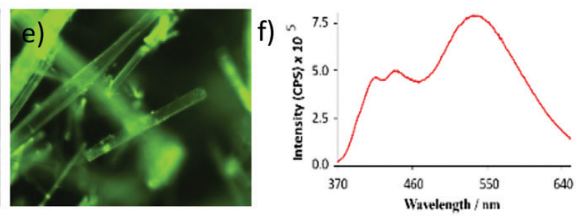

Fig. 1 (a) Amide hydrogen bonding mediated J-type aggregation of NMIGW-OMe in the solid-state. (b) Head to tail interactions of two NMI derivatives through $\mathrm{C}-\mathrm{H} \ldots \mathrm{O}$ hydrogen bonding interactions (oxygen of the naphthalimide unit and tryptophan ring hydrogen). (c) Formation of a helical structure in the solid-state. (d) Optical and (e) fluorescence microscopic images of NMI-OMe crystals and (f) solid-state fluorescence spectra of $\mathrm{NMI}-\mathrm{GW}-\mathrm{OMe}$ at $30{ }^{\circ} \mathrm{C}$

fashion in the solid-state. The compound emitted $\left(\lambda_{\mathrm{ex}}=\right.$ $343 \mathrm{~nm}$ ) characteristic monomeric peaks at 409 and $440 \mathrm{~nm}$ along with a more intense broad excimer peak at $539 \mathrm{~nm} .{ }^{12}$ The highly fluorescent nature of the crystals was also visualized using a fluorescence microscope (Fig. 1e). Temperaturedependent solid-state fluorescence spectroscopy was performed to explore the thermochromic nature of the crystal. The intensity of the excimer peak at $539 \mathrm{~nm}$ was quenched with an increase in temperature from 30 to $100{ }^{\circ} \mathrm{C}$. At $100{ }^{\circ} \mathrm{C}$, the excimer peak (at $539 \mathrm{~nm}$ ) was blue-shifted and its intensity reduced $^{25} 1.6$ times compared to that at $30{ }^{\circ} \mathrm{C}$ (ESI, $\dagger$ Fig. S7). However, controlled-cooling leads to almost full retention of the fluorescence intensity and peak position.

Planar aromatic NMI group containing molecules are also known to form supramolecular gels ${ }^{26-31}$ due to strong aromatic-aromatic interactions among the naphthalimide units. We studied the self-assembly and gelation behaviour of NMIGW-OMe in several common organic solvents (Table 1). Initially, the heating-cooling technique was used to trigger gelation. Samples were dissolved in organic solvents and left for cooling

Table 1 Gelation of NMI-GW-OMe in different organic solvents upon sonication. G, S and I represent gel, solution and insoluble, respectively. The gelation efficiency is given in brackets

\begin{tabular}{llll}
\hline Solvents & Physical state & Solvents & Physical state \\
\hline Chloroform & $\mathrm{S}$ & $N, N$-Dimethyl formamide & $\mathrm{S}$ \\
Methanol & $\mathrm{I}$ & Dimethyl sulphoxide & $\mathrm{S}$ \\
$n$-Butanol & $\mathrm{G}(18 \mathrm{mM})$ & Tetrahydrofuran & $\mathrm{S}$ \\
$n$-Hexanol & $\mathrm{G}(16 \mathrm{mM})$ & 1,4-Dioxane & $\mathrm{S}$ \\
$n$-Octanol & $\mathrm{G}(13 \mathrm{mM})$ & Toluene & $\mathrm{G}(15 \mathrm{mM})$ \\
Allyl alcohol & $\mathrm{S}$ & Xylene & $\mathrm{G}(10 \mathrm{mM})$ \\
Benzyl alcohol & $\mathrm{S}$ & Chlorobenzene & $\mathrm{G}(13 \mathrm{mM})$ \\
Acetonitrile & $\mathrm{S}$ & Cyclopentanone & $\mathrm{S}$
\end{tabular}


at room temperature. In most of the cases, the mixture remained as a solution upon cooling. However, in a few solvents (aromatic solvents and long-chain aliphatic alcohols) viscous precipitations were observed. Later, we noticed that sonication $^{27,30,32-35}$ is an interesting stimulus to induce gelation in this system.

Here, gel formation was noticed in these aromatic solvents and long-chain alcohols after sonication (ESI, $\dagger$ Fig. S8). The details of gelation of NMI-GW-OMe are given in Table 1.

Recently, several emerging properties ${ }^{26,36-43}$ of planar fluorophores have been observed in mixed solvents. One of them is supramolecular gelation. ${ }^{44-61}$ It is clear from the gelation table that the gelator is insoluble in water and soluble in DMSO. We serendipitously observed that the quick addition of water into DMSO solution led to the formation of a self-supported gel. ${ }^{40}$ This is an example of anti-solvent induced gelation. ${ }^{62} \mathrm{We}$ then systematically studied the gelation properties of NMI-GW-OMe by gradually increasing $(10 \%)$ the water fraction in each vial (left to right) containing the DMSO solution of the gelator [gelator conc. $=5 \mathrm{mM}$ ] (Fig. $2 \mathrm{a}$ and b). It was observed that with an increase in the water content $(>50 \%)$, the solution became hazy and viscous. A self-supported supramolecular gel

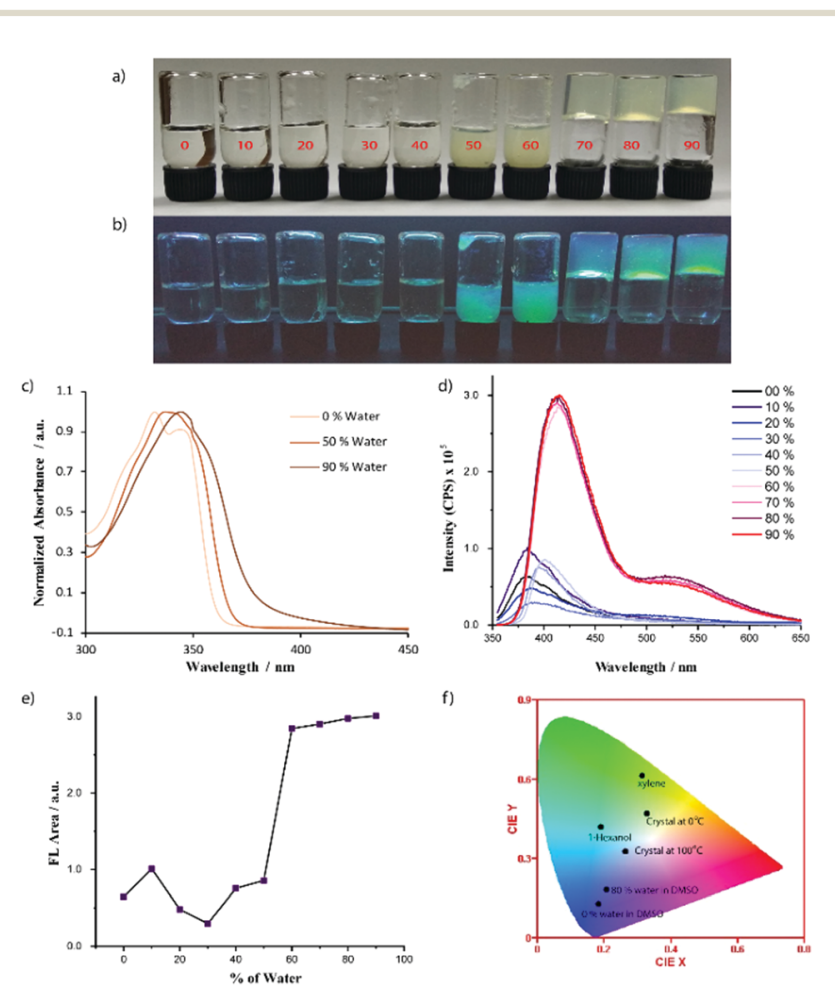

Fig. 2 Solvent induced gelation properties of NMI-GW-OMe (5 mM) in a DMSO-water mixed solvent. From left to right the water content is increased. The $\%$ of water is written on the glass vial. Image of glass vials under (a) normal daylight and (b) UV-light. (c) Normalized absorbance spectra of NMI-GW-OMe at $40 \mu \mathrm{M}$. (d) Solvent-dependent fluorescence spectra of NMI-GW-OMe (3 mM). The \% of water in DMSO is shown in the figure legends. Here, the AIE-property is noticed. (e) Area under the fluorescence spectra (Fig. 2d) of NMI-GW-OMe with the \% of water in the DMSO solution. (f) CIE plot of the fluorescence spectra of NMI-GWOMe in different assembled states.
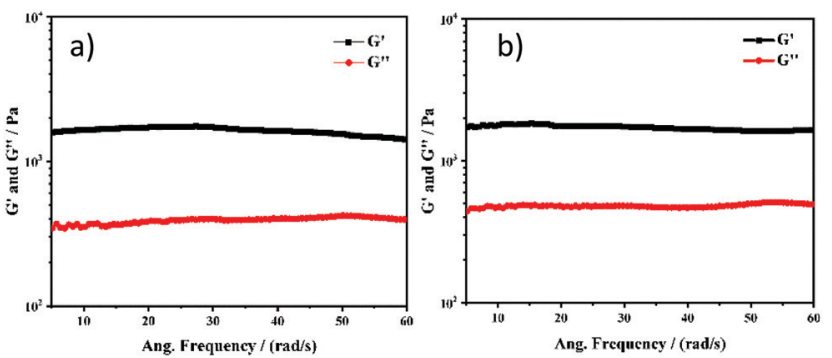

Fig. 3 Frequency sweep experiments of NMI-GW-OMe based supramolecular gels prepared after addition of (a) $70 \%$ water and (b) $90 \%$ water in the DMSO solution of the gelator.

material was observed upon addition of $70 \%$ water in the solution. Moreover, on addition of higher fraction of water, self-supported gels were obtained. The gel formation was supported by a rheological experiment. In a frequency sweep experiment, the storage modulus $\left(G^{\prime}\right)$ value is higher than the loss modulus $\left(G^{\prime \prime}\right)$ value. This is indicative of supramolecular gel formation. ${ }^{32,63}$ The storage modulus value is in the order of $10^{3} \mathrm{~Pa}$. The gel formed after the addition of $90 \%$ water was also investigated by a similar experiment. The storage modulus values in both cases are comparable (Fig. 3).

We studied the gel formation by varying the concentration of the gelator and the \% of added water in the DMSO-water solution. It was observed that the gelator concentration and water content varied inversely. Under UV light (365 nm), cyanblue coloured fluorescence was observed in the aggregated solution and gel state (Fig. 2b). We then explored this process to check whether addition of water can also gelify the solution of the gelator in acetonitrile, DMF, and THF or not. In every case, self-supported gels were obtained (Fig. S9, ESI $\dagger$ ). The details of the gelation study in mixed solvents is given in Table 2 .

With an increase of the water content in the mixed solvents, the self-assembly properties of NMI-GW-OMe were enhanced and this motivated us to investigate the assembly properties using different spectroscopic techniques. NMI-GW-OMe showed an absorption maximum $\left(\lambda_{\max }\right)$ at $333 \mathrm{~nm}$ in pure DMSO medium at $40 \mu \mathrm{M}$ concentration. The molecules were in a non-aggregated state and this absorption maximum corresponded to the $\pi-\pi^{*}$ electronic transition of the naphthalimide unit. In the presence of $50 \%$ and $90 \%$ water in DMSO-water

Table 2 Physical state of NMI-GW-OMe in different mixed solvents. S, V, $G$ and I represent solution, viscous solution, gel and insoluble, respectively

\begin{tabular}{lllll}
\hline$\%$ of water & DMSO & ACN & DMF & THF \\
\hline 10 & S & S & S & S \\
20 & S & S & S & S \\
30 & S & S & S & S \\
40 & S & S & S & S \\
50 & V & V & S & S \\
60 & V & G & V & V \\
70 & G & G & G & G \\
80 & G & G & G & G \\
90 & G & G & G & G \\
100 & I & I & I & I
\end{tabular}


solution, the absorption maximum was shifted to $343 \mathrm{~nm}$ and $347 \mathrm{~nm}$, respectively.

So, a red-shift of the absorption maximum in the UV-vis spectra was observed with the increase of water. In the presence of $90 \%$ water, the absorption maximum shifted almost $14 \mathrm{~nm}$. This red-shift can be considered as a J-type interaction ${ }^{20,64-66}$ among the naphthalimide units. The addition of water into a DMSO solution of the gelator prompts the self-assembly process through $\pi-\pi$ stacking interactions, which favours the red-shift of the absorption peak. To check the stability of the self-assembled structure, we performed a variable-temperature UV-vis study of the gelator (90\% water in DMSO-water solution) and found that the spectral signature of aggregated NMI-GWOMe remained almost invariant even at $50{ }^{\circ} \mathrm{C}$, suggesting its appreciable thermal stability (Fig. S10, ESI $\dagger$ ). We studied the circular dichroism (CD) spectra of the gelator in pure DMSO and DMSO-water mixed solvent. Though a chiral amino acid is present in the system, the CD spectrum is silent in pure DMSO. On addition of water into the DMSO solution of the gelator, new peaks were evolved (Fig. S11, ESI $\dagger$ ). This is an example of chiral induction in the supramolecular state. ${ }^{28,29,67}$

The solvent-dependent fluorescent property of NMI-GWOMe was studied in a mixed solvent (DMSO-water) at $3 \mathrm{mM}$ concentration (Fig. 2d). In DMSO, the emission spectrum exhibited a maximum at $386 \mathrm{~nm}$. In the presence of $50 \%$ water in the DMSO-water solution, the maximum of the emission spectrum was shifted to $402 \mathrm{~nm}$. However, a drastic change in the emission spectrum was noticed with a further increase of the water content in the solution. In the presence of $60 \%$ water, the intensity of the emission spectrum was significantly enhanced. The maximum of the spectrum was further shifted to $416 \mathrm{~nm}$ along with a broad excimer peak at $527 \mathrm{~nm}$. Similar observations were noticed with a further increase in the water content. Here, AIE phenomena were noticed in the presence of a higher content of water. This is an example of a unique molecule that forms J-type aggregates in the solid and solution states. The fluorescent properties of NMI-GW-OMe gels in different aliphatic alcohols and aromatic solvents were studied (Fig. S12, ESI $\dagger$ ). In aliphatic solvents, the maximum of the emission peak centred around 410-425 nm, while in electronrich aromatic solvents a significant red-shift of the emission spectrum was observed. ${ }^{65}$ Based on the different fluorescent properties in the solid and gel (in organic and aqueous solvent) states, a CIE plot of the NMI derivative is shown in Fig. $2 \mathrm{f}$.

To gain more insight into the AIE properties in the mixed solvent, time-correlated single-photon-counting (TCSPC) experiments (Fig. 4) were performed. In DMSO, the emission was monitored at $350 \mathrm{~nm}\left(\lambda_{\text {ex }}=343 \mathrm{~nm}\right)$. A very short-lived decay (2.3 ps) was noted. A similar experiment was performed in $90 \%$ water in DMSO and a substantially longer average lifetime of 463 ps was seen, which is consistent with literature precedent for J-aggregation. ${ }^{24,68}$

The structural features of NMI-GW-OMe have been investigated with the help of DFT calculations. ${ }^{20}$ The energy minimized structures of the compound at the B3LYP and 6-311g(d,p) levels of theory show a structural resemblance with its X-ray

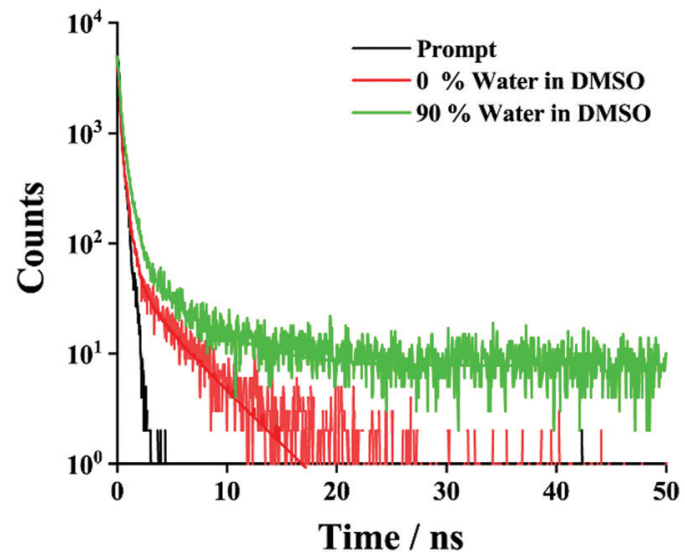

Fig. 4 TCSPC decay profile of NMI-GW-OMe in DMSO and DMSO-water solvent. All samples were excited at $343 \mathrm{~nm}$, and the decay was recorded at $350 \mathrm{~nm}$. In the mixed solvent a longer average lifetime value was noticed.

crystallographically determined structure. However, the optimization of the dimeric structure of NMI-GW-OMe reveals that noncovalent interactions between two molecules are playing the key roles for J-type association. The amide hydrogen and C-H of NMI attached glycine are involved in conventional and carbon hydrogen bonding with the amide carbonyl $(\mathrm{C}=\mathrm{O})$. The $\pi$-stacking between two NMI rings is disturbed somewhat due to this kind of hydrogen bonding and they stayed in a transverse fashion to each other. It is the main driving force of their J-type association. The $\pi$-stacking interaction between two indole moieties also favours this association.

To explore the electronic properties of NMI-GW-OMe, TDDFT calculations have been utilized. The gas phase calculation showed that the HOMO-LUMO band gap of dimeric NMI-GWOMe has a considerable value. The HOMO of the dimer is concentrated over the electron rich indole moiety whereas the LUMO is contributed by the NMI part.

The nanoscale morphologies of the gels were studied in a mixed solvent (90\% water in a DSMO-water solution) and xylene using transmission electron microscopy (TEM). In both cases, a nanofibrillar morphology was noticed. It is clear from Fig. 5 that the nanofibers formed in the mixed solvent are shorter in length compared to the nanofibers formed in xylene. The average diameters of the gel nanofibers in the DMSO-water and xylene solvents are $15.6 \pm 3.1$ and $19.0 \pm 3.2 \mathrm{~nm}$, respectively. Xerogel materials (prepared from mixed solvents) were investigated a)

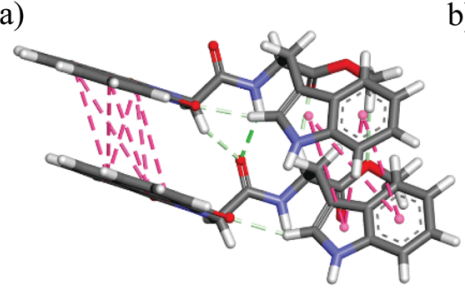

b)

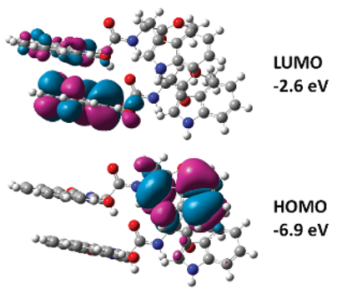

Fig. 5 (a) DFT [B3LYP/6-311g(d,p)]-optimised dimeric structure of NMIGW-OMe. (b) Frontier molecular orbitals of the NMI derivative. 


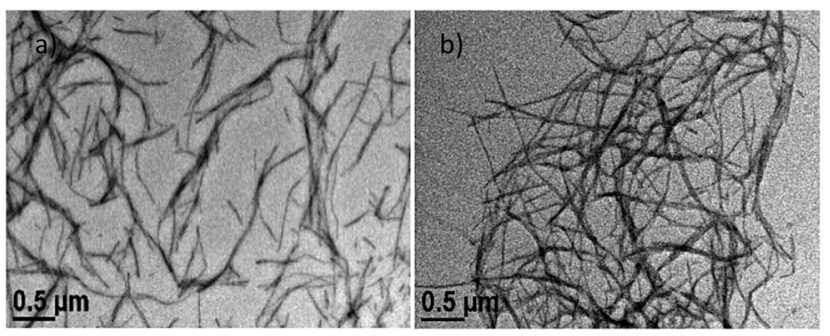

Fig. 6 Nanofibrillar morphology of the gel in (a) DMSO-water and (b) xylene solvent.

using fluorescence microscopy. A greenish-coloured fibrillar morphology was observed through the fluorescence microscopy due to the AIE property (Fig. S13, ESI $\dagger$ ).

To envisage the supramolecular structure in the gel network, ${ }^{69}$ we employed powder X-ray diffraction (PXRD) on the gel obtained from DMSO- $\mathrm{H}_{2} \mathrm{O}$ medium (Fig. 7). Gel state PXRD study often exhibits poor crystallinity, but reveals the authentic packing pattern in the gel state. ${ }^{70}$ Here, the poor crystallinity widens the PXRD pattern in the gel state. While comparing it with the simulated XRD pattern of the NMI-GW-OMe crystal, the major peak positions remain intact. It depicts the presence of a quite similar packing pattern in the gel state (Fig. 6).

Inspired by the AIE property, the gelator was used in a cell imaging study. Before utilizing it for cells, the cytotoxicity of the gelator was evaluated using MTT assay at $37{ }^{\circ} \mathrm{C}$ by incubating with HADF cells for $24 \mathrm{~h}$. The results depicted that the cellular viability at 65,130 and $260 \mu \mathrm{M}$ remains $\sim 98,84$ and $75 \%$, respectively, indicating less cytotoxicity (Fig. 8a). The cellular viability was found to decrease to $60 \%$ after incubating the cells with $325 \mu \mathrm{M}$ NMI-GW-OMe. The cells are almost viable in the presence of $65 \mu \mathrm{M}$ gelator, indicating its biocompatibility for living cells. In vitro assessment of HADF cells was done by incubating the gelator for $24 \mathrm{~h}$ at $37{ }^{\circ} \mathrm{C}$. It is evident from Fig. S14 (ESI $\dagger$ ) that the HADF cells were not showing any background fluorescence signal. On incubating with $65 \mu \mathrm{M}$ NMI derivative, the HADF cells showed prominent green fluorescence,

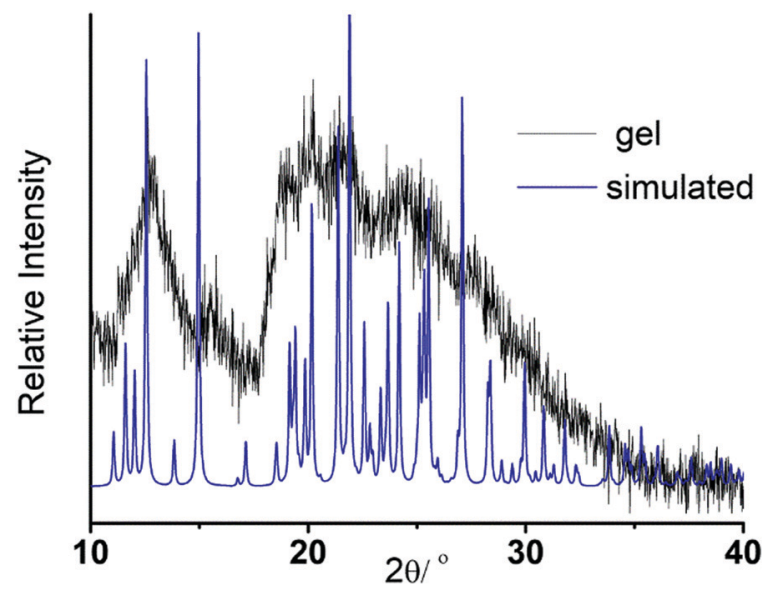

Fig. 7 Comparison of the PXRD pattern of the gel in DMSO-water solvent with the simulated XRD pattern of the NMI-GW-OMe crystal.
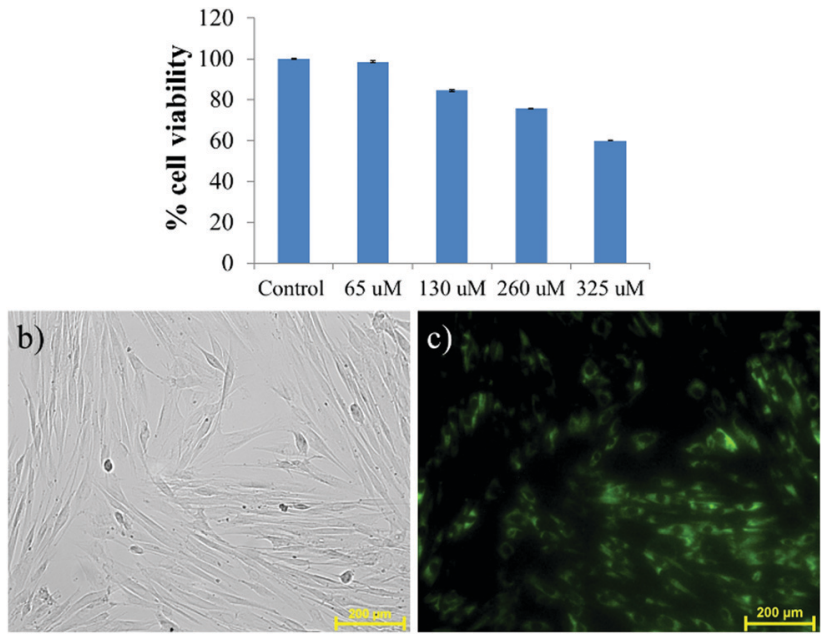

Fig. 8 (a) Viability of HADF cells after $24 \mathrm{~h}$ of treatment with different concentrations of NMI-GW-OMe (65 to $325 \mu \mathrm{M})$, determined by MTT assay. (b) Bright field and (c) fluorescence images of HADF cells were captured $(20 \times)$ after incubation with $65 \mu \mathrm{M}$ NMI derivative.

Fig. 8c. This result implied that this naphthalimide derivative could be used as an efficient candidate for live cell imaging.

\section{Conclusions}

In summary, we designed and synthesized an unsubstituted naphthalimide based dipeptide to demonstrate its photophysical properties in the solid and self-assembled state. We noticed that the structurally simple fluorogen exhibits J-type aggregation in the solid, solution, and gel state. We discussed the different structural aspects of this naphthalimide derivative in the solid-state. Here, an amide hydrogen bonding interaction guides the arrangement of unsubstituted naphthalimide groups in the J-type fashion. In the solution and gel states, J-type aggregation was confirmed by different spectroscopic techniques. The aggregation-induced enhancement of emission phenomenon in aqueous solution was used for live cell imaging. The conjugates of the 1,8-naphthalimide unit with a naturally occurring peptide can be an excellent combination as a fluorescent probe for future applications in biology. The naphthalimide units can be easily modified by chemical reactions to incorporate additional functionality for tailor-made fluorescence and self-assembly properties. In the future, these kinds of AIEgens having low cytotoxicity and longer lifetime can be used as a probe for studying the biological functions and pathological effects in the sub-cellular structure.

\section{Conflicts of interest}

There are no conflicts to declare.

\section{Acknowledgements}

JN gratefully acknowledges DST-INSPIRE Faculty Grant (IFA16CH246) and Department of Chemistry, IIEST-Shibpur, for 
financial assistance. P. Brandão acknowledges the financial support from the project CICECO-Aveiro Institute of Materials, UIDB/50011/2020 \& UIDP/50011/2020, financed by national funds through the FCT/MEC and by FEDER under the PT2020 Partnership Agreement.

\section{Notes and references}

1 Y. Hong, J. W. Y. Lam and B. Z. Tang, Chem. Soc. Rev., 2011, 40, 5361-5388.

2 C. Gui, E. Zhao, R. T. K. Kwok, A. C. S. Leung, J. W. Y. Lam, M. Jiang, H. Deng, Y. Cai, W. Zhang, H. Su and B. Z. Tang, Chem. Sci., 2017, 8, 1822-1830.

3 N. Meher, S. Panda, S. Kumar and P. K. Iyer, Chem. Sci., 2018, 9, 3978-3985.

4 C. Zhu, R. T. K. Kwok, J. W. Y. Lam and B. Z. Tang, ACS Appl. Bio Mater., 2018, 1, 1768-1786.

5 X. Cai and B. Liu, Angew. Chem., Int. Ed., 2020, 59, 9868-9886.

6 Z. Zhao, H. Zhang, J. W. Y. Lam and B. Z. Tang, Angew. Chem., Int. Ed., 2020, 59, 9888-9907.

7 F. Würthner, Angew. Chem., Int. Ed., 2020, 59, 14192-14196. 8 J. Luo, Z. Xie, J. W. Y. Lam, L. Cheng, H. Chen, C. Qiu, H. S. Kwok, X. Zhan, Y. Liu, D. Zhu and B. Z. Tang, Chem. Commun., 2001, 1740-1741.

9 B.-K. An, S.-K. Kwon, S.-D. Jung and S. Y. Park, J. Am. Chem. Soc., 2002, 124, 14410-14415.

10 S. Banerjee, E. B. Veale, C. M. Phelan, S. A. Murphy, G. M. Tocci, L. J. Gillespie, D. O. Frimannsson, J. M. Kelly and T. Gunnlaugsson, Chem. Soc. Rev., 2013, 42, 1601-1618.

11 R. M. Duke, E. B. Veale, F. M. Pfeffer, P. E. Kruger and T. Gunnlaugsson, Chem. Soc. Rev., 2010, 39, 3936-3953.

12 N. Meher and P. K. Iyer, Nanoscale, 2019, 11, 13233-13242.

13 Z. Chen, D. Wu, X. Han, Y. Nie, J. Yin, G.-A. Yu and S. H. Liu, RSC Adv., 2014, 4, 63985-63988.

14 L. Zhu, X. Li, Q. Zhang, X. Ma, M. Li, H. Zhang, Z. Luo, H. Ågren and Y. Zhao, J. Am. Chem. Soc., 2013, 135, 5175-5182.

15 N. Meher and P. K. Iyer, Angew. Chem., Int. Ed., 2018, 57, 8488-8492.

16 Y. Ni, Z. Sun, Y. Wang, H. F. Nour, A. C. H. Sue, N. S. Finney, K. K. Baldridge and M. A. Olson, J. Mater. Chem. C, 2019, 7, 7399-7410.

17 M. Poddar, G. Sivakumar and R. Misra, J. Mater. Chem. C, 2019, 7, 14798-14815.

18 C. Balachandra and T. Govindaraju, J. Org. Chem., 2020, 85, 1525-1536.

19 S. Jena, P. Dhanalakshmi, G. Bano and P. Thilagar, J. Phys. Chem. B, 2020, 124, 5393-5406.

20 S. Mukherjee and P. Thilagar, Chem. - Eur. J., 2014, 20, 8012-8023.

21 P. Gopikrishna, N. Meher and P. K. Iyer, ACS Appl. Mater. Interfaces, 2018, 10, 12081-12111.

22 F. Würthner, T. E. Kaiser and C. R. Saha-Möller, Angew. Chem., Int. Ed., 2011, 50, 3376-3410.
23 E. E. Greciano, J. Calbo, E. Ortí and L. Sánchez, Angew. Chem., Int. Ed., 2020, 59, 17517-17524.

24 T. E. Kaiser, H. Wang, V. Stepanenko and F. Würthner, Angew. Chem., Int. Ed., 2007, 46, 5541-5544.

25 A. Gładysiak, T. N. Nguyen, R. Bounds, A. Zacharia, G. Itskos, J. A. Reimer and K. C. Stylianou, Chem. Sci., 2019, 10, 6140-6148.

26 C. Felip-León, F. Galindo and J. F. Miravet, Nanoscale, 2018, 10, 17060-17069.

27 X. Pang, X. Yu, H. Lan, X. Ge, Y. Li, X. Zhen and T. Yi, ACS Appl. Mater. Interfaces, 2015, 7, 13569-13577.

28 S.-M. Hsu, F.-Y. Wu, H. Cheng, Y.-T. Huang, Y.-R. Hsieh, D. T.-H. Tseng, M.-Y. Yeh, S.-C. Hung and H.-C. Lin, Adv. Healthcare Mater., 2016, 5, 2406-2412.

29 Q. N. Pham, N. Brosse, C. Frochot, D. Dumas, A. Hocquet and B. Jamart-Grégoire, New J. Chem., 2008, 32, 1131-1139.

30 K. Liu, L. Meng, S. Mo, M. Zhang, Y. Mao, X. Cao, C. Huang and T. Yi, J. Mater. Chem. C, 2013, 1, 1753-1762.

31 M. Kumar, D. Sementa, V. Narang, E. Riedo and R. V. Ulijn, Chem. - Eur. J., 2020, 26, 8372-8376.

32 B. Adhikari, J. Nanda and A. Banerjee, Chem. - Eur. J., 2011, 17, 11488-11496.

33 C. G. Pappas, P. W. J. M. Frederix, T. Mutasa, S. Fleming, Y. M. Abul-Haija, S. M. Kelly, A. Gachagan, D. Kalafatovic, J. Trevino, R. V. Ulijn and S. Bai, Chem. Commun., 2015, 51, 8465-8468.

34 S. Maity, P. Das and M. Reches, Sci. Rep., 2015, 5, 16365.

35 J. M. Malicka, A. Sandeep, F. Monti, E. Bandini, M. Gazzano, C. Ranjith, V. K. Praveen, A. Ajayaghosh and N. Armaroli, Chem. - Eur. J., 2013, 19, 12991-13001.

36 S. S. Babu, V. K. Praveen and A. Ajayaghosh, Chem. Rev., 2014, 114, 1973-2129.

37 P. A. Korevaar, C. Schaefer, T. F. A. de Greef and E. W. Meijer, J. Am. Chem. Soc., 2012, 134, 13482.

38 D. Ivnitski, M. Amit, O. Silberbush, Y. Atsmon-Raz, J. Nanda, R. Cohen-Luria, Y. Miller, G. Ashkenasy and N. Ashkenasy, Angew. Chem., Int. Ed., 2016, 55, 9988-9992.

39 Y. Lan, M. G. Corradini, R. G. Weiss, S. R. Raghavan and M. A. Rogers, Chem. Soc. Rev., 2015, 44, 6035-6058.

40 J. Raeburn, C. Mendoza-Cuenca, B. N. Cattoz, M. A. Little, A. E. Terry, A. Zamith Cardoso, P. C. Griffiths and D. J. Adams, Soft Matter, 2015, 11, 927-935.

41 V. W.-W. Yam, K. M.-C. Wong and N. Zhu, J. Am. Chem. Soc., 2002, 124, 6506-6507.

42 P. Singh, S. Misra, N. Sepay, S. Mondal, D. Ray, V. K. Aswal and J. Nanda, Soft Matter, 2020, 16, 6599-6607.

43 J. S. Valera, R. Sánchez-Naya, F. J. Ramírez, J. L. Zafra, R. Gómez, J. Casado and L. Sánchez, Chem. - Eur. J., 2017, 23, 11141-11146.

44 S. Biswas, M. Kumar, A. M. Levine, I. Jimenez, R. V. Ulijn and A. B. Braunschweig, Chem. Sci., 2020, 11, 4239-4245.

45 L. S. Birchall, S. Roy, V. Jayawarna, M. Hughes, E. Irvine, G. T. Okorogheye, N. Saudi, E. De Santis, T. Tuttle, A. A. Edwards and R. V. Ulijn, Chem. Sci., 2011, 2, 1349-1355. 46 K. Hawkins, A. K. Patterson, P. A. Clarke and D. K. Smith, J. Am. Chem. Soc., 2020, 142, 4379-4389. 
47 J. Ruíz-Olles and D. K. Smith, Chem. Sci., 2018, 9, 5541-5550.

48 P. Slavík, D. W. Kurka and D. K. Smith, Chem. Sci., 2018, 9, 8673-8681.

49 A. Mahler, M. Reches, M. Rechter, S. Cohen and E. Gazit, Adv. Mater., 2006, 18, 1365-1370.

50 G. Liu, J. Sheng, H. Wu, C. Yang, G. Yang, Y. Li, R. Ganguly, L. Zhu and Y. Zhao, J. Am. Chem. Soc., 2018, 140, 6467-6473.

51 G. Liu, C. Zhou, W. L. Teo, C. Qian and Y. Zhao, Angew. Chem., Int. Ed., 2019, 58, 9366-9372.

52 D. E. Clarke, C. D. J. Parmenter and O. A. Scherman, Angew. Chem., Int. Ed., 2018, 57, 7709-7713.

53 C. Rest, M. J. Mayoral, K. Fucke, J. Schellheimer, V. Stepanenko and G. Fernández, Angew. Chem., Int. Ed., 2014, 53, 700.

54 S. Ghosh, V. K. Praveen and A. Ajayaghosh, Annu. Rev. Mater. Res., 2016, 46, 235-262.

55 S. Cherumukkil, S. Ghosh, V. K. Praveen and A. Ajayaghosh, Chem. Sci., 2017, 8, 5644-5649.

56 A. R. Hirst, B. Escuder, J. F. Miravet and D. K. Smith, Angew. Chem., Int. Ed., 2008, 47, 8002-8018.

57 A. Ajayaghosh, S. J. George and V. K. Praveen, Angew. Chem., Int. Ed., 2003, 42, 332-335.

58 D. B. Amabilino, D. K. Smith and J. W. Steed, Chem. Soc. Rev., 2017, 46, 2404-2420.
59 S. Saha, J. Bachl, T. Kundu, D. Díaz Díaz and R. Banerjee, Chem. Commun., 2014, 50, 3004-3006.

60 C. Rest, R. Kandanelli and G. Fernández, Chem. Soc. Rev., 2015, 44, 2543-2572.

61 N. Bäumer, K. K. Kartha, J. P. Palakkal and G. Fernández, Soft Matter, 2020, 16, 6834-6840.

62 P. Sahoo, D. K. Kumar, S. R. Raghavan and P. Dastidar, Chem. - Asian J., 2011, 6, 1038-1047.

63 P. Singh, S. Misra, A. Das, S. Roy, P. Datta, G. Bhattacharjee, B. Satpati and J. Nanda, ACS Appl. Bio Mater., 2019, 2, 4881-4891.

64 S. Basak, J. Nanda and A. Banerjee, Chem. Commun., 2013, 49, 6891-6893.

65 S. Basak, N. Nandi, A. Baral and A. Banerjee, Chem. Commun., 2015, 51, 780-783.

66 E. E. Greciano, J. Calbo, E. Ortí and L. Sanchez, Angew. Chem., Int. Ed., 2020, 59, 17517-17524.

67 D. A. Shejul, S. M. Wagalgave, R. W. Jadhav, M. A. Kobaisi, D. D. La, L. A. Jones, R. S. Bhosale, S. V. Bhosale and S. V. Bhosale, New J. Chem., 2020, 44, 1615-1623.

68 A. Ajayaghosh, V. K. Praveen, C. Vijayakumar and S. J. George, Angew. Chem., Int. Ed., 2007, 46, 6260-6265.

69 P. Sahoo and P. Dastidar, Cryst. Growth Des., 2012, 12, 5917-5924.

70 P. Sahoo, V. G. Puranik, A. K. Patra, P. U. Sastry and P. Dastidar, Soft Matter, 2011, 7, 3634-3641. 